\section{Anthropological and psychoanalytical observation: theoretical and methodological dialogues in a doctorate programme in mother and child health}

\section{Observação antropológica e psicanalítica: diálogos teórico-metodológicos num programa de doutorado em saúde materno infantil}

Marisa Amorim Sampaio 1

Ana Rodrigues Falbo 2

Katia Virginia de O. Feliciano 3

Maria do Carmo Camarotti 4

Michael Rustin 5

Lisa Miller 6

1-3 Instituto de Medicina Integral Prof. Fernando Figueira. Rua dos Coelhos, 300. Boa Vista. Recife, PE, Brasil. CEP: 50.070-550.

E-mail: marisasampaio@hotmail.com

4 Faculdade de Ciências Médicas da Paraíba. João Pessoa, PB, Brasil

5 University of East London. London, UK.

6 Tavistock Clinic. London, UK.

\begin{abstract}
Participant observation can vary considerably depending on the theoretical inspiration, nature/design of the research and relationship researcher-subjects. In the ethnographic study developed in Brazil (July 2009 - August 2010), among other techniques used, Bick's observation (rooted in psychoanalysis) was introduced and adapted. The aim was to understand processes involved in the communication between professionals at a Family Health Strategy and mothers/dyads (mother-baby) about breast feeding. Based on this study, a sandwich project was designed: to develop a deeper understanding of Bick's theoretical and practical approach, its relevance for research and broader applications; to promote a transdisciplinary dialogue between anthropological and psychoanalytic observation. As a student at Tavistock (UK) I attended seminars and developed observations in another variation of the setting. Aware of the ethics of the method, Tavistock has been widening its'scope, not seeing it as a unique model, but a comprehensive way of thinking human uniqueness, facilitating the researcher's capacity for self-analysis and a diversity of applications. Although my reflections are preliminary, the potential of Bick's to innovate research methods cannot be ignored. In the contemporary field of mother-child health we do not face a single concept of science, but new/renewed paradigms of thought and diversity of methods.

Key words Ethnography, Psychoanalysis, Motherchild relations, Breast feeding, Comprehensive health care
\end{abstract}

\section{Resumo}

A observação participante pode variar consideravelmente dependendo da inspiração teórica, natureza/desenho do estudo e da relação pesquisadorsujeitos. Num estudo etnográfico desenvolvido no Brasil (Julho 2009 - Agosto 2010), dentre outras técnicas utilizadas, a observação Bick (ancorada na psicanálise) foi introduzida e adaptada. O objetivo foi compreender os processos envolvidos na comunicação profissionais da Estratégia de Saúde da Família e mãe/diades (mãe-bebê) sobre amamentação. Com base neste, um projeto sanduiche foi concebido visando: desenvolver compreensão aprofundada da abordagem teórico-prática do método Bick, sua relevância para a pesquisa e aplicações abrangentes; promover diálogo transdisciplinar entre observação antropológica e psicanalítica. Como estudante na Tavistock (Reino Unido) participei de seminários e desenvolvi observações noutra variação do setting Bick. Ciente da ética do método, a Tavistock tem abrangido seu escopo, não tomando o Bick como um modelo único a ser seguido, mas um modo abrangente de abordar a singularidade humana, promovendo a capacidade auto-analítica do pesquisador e uma diversidade de aplicações. Apesar das reflexões ainda serem preliminares, o potencial do Bick para inovar métodos de pesquisa não pode ser ignorado. No campo atual da saúde materno infantil não lidamos com um conceito único de ciência, porém paradigmas de pensamento novos/renovados e uma diversidade de métodos.

Palavras-chave Etnografia, Psicanálise, Relações mãe-filho, Aleitamento materno, Assistência integral à saúde 


\section{Introduction}

Participant observation can vary considerably depending on the theoretical inspiration, nature and design of the research, and the relationship researcher-subjects. In the ethnographic doctorate study developed in Brazil (between July 2009 and August 2010), which was referenced on the hermeneutic-dialectics and psychoanalysis, among other techniques used (observations, semi-structured interviews and documents relating to the daily practice and the context of the clinical situation), Bick's infant observation (an observational method rooted in psychoanalysis) was introduced and adapted into the ethnography. The aim was to help understand the processes involved in the communication between professionals at a Family Health Strategy and mothers/dyads (mother-baby) about breast feeding. It addressed the conscious and unconscious meanings and practices around breast feeding promotion and dyad interaction, developing a sense of the different realities in operation (from the professionals and families), and a sense of the inner worlds observed in depth (mother and baby), analysing possibilities in the construction of motherhood and feeding relationships.

Based on this study, a sandwich project was designed involving ambitious objectives: to develop a deeper understanding of the theoretical and practical approach at Tavistock (the institution where the Bick method was created in 1949, in London), its relevance for research and broader applications; to promote a transdisciplinary dialogue between anthropological and psychoanalytic observation regarding intersubjective exchanges experienced in fieldwork. Can these two perspectives, distinct ways of framing the study of persons and interactions, be productively combined, and what follows if one combines them, can they be used beneficially?

There are common epistemological principles (means of knowing) for anthropology and psychoanalysis: both conceive reality as mediated by language, using close observation and accurate description to stress the process of interaction in fieldwork and the creation of meanings. Not so different from anthropology, Bick's method requires from the observer openness to the unexpected in fieldwork,

\footnotetext{
"an ability to hold in mind a loose cluster of expectations and conceptions, while remaining open to the experiences of the observation as it develops, (...) prepared to respond to and think about new experiences, both of the families observed and of himself, which may not easily or imme-
}

diately relate to (the observer's) preconceptions at all" (p.

57). 1

The challenge to achieve a balance between subjectivity and intersubjectivity is a complex negotiation; hermeneutic-dialectics and psychoanalysis seek it through different means. The researcher does not need to abdicate his own culture/horizon of understanding/perspective, but to contextualise it, developing an increased critical sense of his preconceptions. Guided by different cultures/histories/ interests/desires, one may seek provisional descriptions/agreements/meanings, an expression of the diversity of knowledge and experience. There is never a full knowledge of oneself or of the other; in all cases interpretation is understood as contextualized and provisional, a version among the many possible.

In the ethnographic encounter, the researcher opens his horizon, conscious of the different cultural contexts. This dialogical relationship between observer and observed will not reproduce the model of the other, but will seek a 'dense description', a description of meanings. 2

Considering hermeneutic-dialectics, understanding is produced from dialogue, with meanings being negotiated in the act of interpretation, not simply discovered. The interweaving of small facts and meanings will allow a "thick description" of daily interactions. Habermas 3,4 identifies two types of communication: a factual consensus achieved through daily communication, based on the ideas that exist and work behind us, and the discourse constructed through dialogue, by individuals positioned before a "validity of claims" which can be questioned, setting meanings and values as objects of discussion. Thus, truths previously considered valid and unshaken can be questioned, the norms and values must be justified, and social relations considered as a result of a negotiation in which one seeks a provisional understanding. The conditions to dialogue result from the roles played by the subjects, an expression of the intertwining of language and power. ${ }^{5}$ Knowledge is achieved by means of this dialogic relationship, enabling a "fusion of the horizon of expectations", transforming both observed and observer, situated in different semantic fields and yet in symmetrical positions. ${ }^{6}$

Freud showed how internally divided and nontransparent to ourselves we are, far from being a 'unified subject', and our dependence on our experience and on non-symmetrical relations to others. A deep and yet partial knowledge may be reached through close observation and an understanding of 
transferencial phenomena.

Even though there are similarities in these approaches, anthropological studies oriented by hermeneutic-dialectics aim to achieve closeness to the subjective experience of the studied (their subjective meanings constituting the social relationship) to represent the social-cultural context of a particular reality. Their 'object of observation' is different from that of psychoanalysis. It usually does not make reference to the researcher's subjectivity (by means of unconscious aspects) as an instrument of 'knowing', even though they legitimise the knowledge of intersubjectivity knowledge within experience.

In psychoanalytical observation, the ontology is that of a field of conscious and unconscious interactions. A lot of what is observed is pre- linguistic, because of transferential phenomena and the knowledge that on the baby's side, the capacity to use language develops from interactions outside or prior to language. This understanding takes place through unconscious communications from baby to mother and from mother to baby, most of them pre-verbal, involved with physical bodies and their sensations, out of which consciousness, subjectivity and intersubjectivity develop.

Although the reflections are still preliminary, one cannot ignore the potential of psychoanalysis and more specifically Bick's observation to stimulate and innovate research methods, generating new ideas in such discussions. ${ }^{1}$ Perhaps a hypothesis can be formulated and negotiations emerge from the process of looking at both inward meanings and outward into the realm of shared meanings, interaction and discourse, with awareness of such a 'meeting of subjectivities' in fieldwork.

\section{Bick's infant observation}

Acknowledged as "a remarkable invention", 7 Bick's infant observation has lead to various applications and singular discoveries about the interaction between the unconscious upon conscious activities. Although it might seem simple, it addresses a complex process; variations in the setting and dialogues with other disciplines need to be carefully considered, not to be unduly disregarded.

At this point it is important to give a brief description of this method as originally proposed. 8 After a preliminary visit to the family (before or soon after the baby's birth), the observer goes to their home regularly, usually once a week, one hour per visit, for one or two years. When observing, it is essential to develop an unobtrusive, non-interfering position, trying to concentrate on the infant/the mother-infant dyad and to take in as much as possible of what happens. ${ }^{9}$ No notes are taken at this moment; soon afterwards comes the writing up of what is remembered, a description in as much detail as possible of the actions and interactions, what was experienced and felt, using non-theoretical language in order to discourage the imposition of preconceptions. The aim is to create "a space in which the phenomena of the observations can register themselves in all their complexity in the mind before the attempt is made to encode them in theoretical terms" (p. 57). ${ }^{1}$

The written observations are subsequently discussed in a seminar group (no more than eight members), meeting on a weekly basis, where one observation is read per day, exchanging impressions so that the observational material itself may be fully explored and digested, also learning about the infant and families observed by the colleagues. 1,9 During this part of the process, it is essential to contain anxieties while seeking to improve the 'analytic tool of the observer' (understanding transference phenomena to avoid performing a role), to develop a capacity for self-analysis, and to try to be more objective in the work of constructing meanings.

\section{A sandwich experience at Tavistock}

This manuscript was derived from a study developed in Brazil and from a sandwich programme at Tavistock Clinic (London), both part of a doctorate in Maternal and Child Health, sponsored by Coordenação de Aperfeiçoamento de Pessoal de Nível Superior (CAPES) an agency under the auspices of the Ministry of Education of Brasil. This cooperative institutional work between the Instituto de Medicina Integral Prof. Fernando Figueira (IMIP) and Tavistock allowed the student to take advantage of a more comprehensive cross-fertilisation. The duration of the programme varies from four to twelve months, with the student's activities being supervised during this period.

Being a student at Tavistock for five months in 2011 meant initially witnessing different cultural and institutional applications of infant observation throughout the world, as part of the " 6 th International Conference for Teachers of Infant and Young Child Observation". Then I had the chance to attend six weekly seminars (September - December): two on infant observation, two on young child observation, a seminar on work discussion and another one on eating disorders.

This psychoanalytical observation proposed by 
Bick does not depend only on the family being observed and on the observer's striving to retain and understand in depth the emotional impact on interactions. The crucial task of containing anxieties and refraining from action also involves a team. At Tavistock, a leader in pioneering mental health practices, theories, treatments, training and research, the team included students and experienced seminar leaders/facilitators, building up an open, creative dialogue.

Having used Bick before in an adapted way and considering that my main motivations for studying at Tavistock was to further dialogues about the use of Bick within ethnography, some questions emerged. What if I had the chance to develop Bick observations during the three months I had left in the UK? How could this short time period (another adaptation of the setting) affect the observation/ observed/observer? How would we cope with these extra anxieties (about entering into the family's intimate space and then leaving and leaving shortly afterwards, while also being in another culture/ language)? The excellence of Tavistock gained greater meaning when my personal tutor and seminar leader, Mrs. Lisa Miller, with nurturing and stimulating examples, and other seminar leaders supported me in this challenge. I had the privilege of observing a toddler at home and premature twins in a neonatal unit.

Although short in time, not allowing the acknowledgement of long term patterns, the observations were intense and impactful. I can only convey to a limited extent in this brief communication the use of the observations in the seminars and lessons from the programme.

Differently from what one might think, it wasn't hard to find a toddler's family willing to be observed, perhaps because of unconscious needs/demands from the parents. At a time of generally suspicious feelings and alleged security concerns among institutions, in order to develop observations at the neonatal unit I was helped by key people who stood close and negotiated the observations. The interpretations of the material and discussions illustrated the anguished and subtle process of finding an appropriate place/position within the family's and institution's intimate space, while also coping with the closure of the observations.

\footnotetext{
Maud led us to her room. (...) I asked her if I could sit on one of the chairs and she said "yes", still shy. Again, we exchanged social smiles. At first I was like "Goldilocks" when I found myself wondering if the chair was strong enough to bear my body, (...) but it seemed strong. Maria
}

(mother) kneeled on the floor to help Maud take her clothes off, adding that she had recently learned to unbutton clothes. Maud was very excited about this unbuttoning thing, doing her best. She then showed me her pink Hello Kitty panties, to which I replied "nice!", finally receiving an authentic smile from Maud. I was glad I was a girl. But still, I tried not to stress this observational moment, giving mother and daughter some privacy at this intimate time. I looked around to notice other details in Maud's room. Throughout this observation I felt that I had gone from being audience/girl/ observer, to being welcomed inside the mother-daughter intimacy.

Maria was - like me - from another country, a speaker of a Latin language, trying to transmit her culture and language to Maud, but most of the time they spoke in English, her husband's native tongue. Although I was among three languages, when with the family I didn't think in my native tongue, feeling that those moments were somehow beyond language: perhaps part of a space between us. Sometimes I felt as if I had forgotten my language and where I was, living the paradox of feeling 'in the air', yet having my feet on the ground.

I noted that mother and daughter also didn't seem to realize when they went from one language to another, but I was able to observe the pattern that they used the mother's native language at very intimate moments. Beyond its social use, a language relates to the way in which the unconscious belief and assumptions that constitute an individual/family culture are projected and introjected, 10 as the subject expresses them through 'holes' in the discourse. The closeness between the construction of scientific data and infant observation gained meaning: behaviour, gestures, words are loaded with a penumbra of implications, since observing, feeling and thinking are inseparable. 8

The Christmas holidays helped to close this brief and intense observation. Mother asked for and was able to wait for some feedback at the end; with this I was hopefully able to facilitate a 'thinking of' in order to provide a future 'thinking about'. As a concrete gesture, I gave Maud a gardening set, so she could plant something to think about in her beloved garden. During the observation Maud kept herself busy with the season's parties, a variation of her usual wary way of not getting too close, perhaps an expression of her symbolic capacity to hold in mind the absent sustaining object, coping with the hardness of a reality full of goodbyes. Maria kept forgetting and yet she was regretful about the forthcoming end of the observations. On the last day 
important 'details' of why she had wanted the observation were then released in quite an emotionally charged way. Father arrived at the very end, taking time to talk about himself as a distant and successful entity, yet surprisingly speaking some words in my language, perhaps not wanting to separate - he was the one who originally wanted the observation. For me it was impossible not to feel incomplete, confronted with the method's and my own limitations. Recalling the connection between absence, limits and thought, I can only hope this process was a spur to all our lives.

My observations at the neonatal unit revealed the impact of this particular institution and several uncertainties, enabling me to glimpse a certain powerlessness among the adults (the observer, hospital staff and parents) towards the vulnerability of the twin babies. Although they were not in a critical clinical state, at first it was exhausting to observe for longer than 30 minutes. I wondered if I would be able to convey into English the primitive feelings I had when with the babies.

For some days I observed the twins alone, as mother and father were not able to be at the hospital. During the first observations silence took hold of me, but unlike with the observation with the toddler, an urge to use my native 'maternal' language emerged.

\footnotetext{
The twins had their head turned to each other, but there was a blanket blocking their view. I took the blanket off and approached each cot, saying in Portuguese, "good evening, boys", with a smile on my face. (...) Although I felt I was watching over them, it was impossible not to feel the presence of the parent's absence, the impact of their empty space. Seated on the arm of the chair beside twin 2, I recognized a song coming from the radio ("Need you") and the lyrics seemed to 'wrap up' what I was feeling: where were the parents? Why was it so hard for them to be with the babies? The song said: "and I wonder if I ever cross you mind... For me it happens all the time. It's a quarter after one, I'm all alone and I need you now. (...) And I don't know how I can do without, I just need you now...". I realised that I was not taking mum's or dad's place on the chair: I just sat on the arm, hoping they would come to take the seat, to speak their language, to say their own words.
}

As the babies started to recover, mother's presence became constant. She had a precarious belief in herself, expecting an expert explanation about her own babies. Mother was expressing milk, but despite the efforts of the staff, she didn't feel able to breastfeed. Bearing her projections, by restraining impulse to relieve anxieties, by building a dialogue about our impressions of the babies and sharing their primitive psychic organization, perhaps the observations helped to sustain mother's attention towards the twins, providing a 'reflective space'. I felt at some level her reverie was being facilitated and encouraged. Some days later, mother commented she wanted to breastfeed the babies at home.

In order to accept the behaviour around me and the emotional atmosphere, my urge was to deconstruct old ideas, enhancing empathy, trying not to judge mother and staff, understanding that every baby is unique and develop different relationships, despite being so helpless. Although their medical needs were primary, it was wonderful to watch the benefits when the babies received something maternal.

The process of closure with this family was not properly concluded. Father, who at first didn't seem to recognize any purpose to the observation (he thought babies don't do anything besides sleep and pooh), although allowing it, faced with the coming end, 'joked' twice, in a 'seductive' way: he wanted the observation to continue at their home. Was he afraid of his wife's abilities? Did he come to find a purpose of my observation/presence with the babies? Mother, in spite of the fact that she and I had set the last observation for her last rooming in day in the hospital, left one day earlier than programmed. When I arrived at the hospital I felt the impact of the empty space, feeling left out, as a part of me had been prematurely taken away without notice, perhaps a projection from the mother. I hope the empty space for me meant for the babies a full space with a mother and a father.

The support needed to contain anxieties came from my participation in seminars, sharing similar experiences with colleagues, helping to reorganise the apparent confusion, reminding me to rely on consecutive observation in order to understand patterns and changes in them. Despite being twins, each baby has a different pace of development, and relates in a particular way to the mother. Whilst the observation was the place for feeling, the seminars represented extra reflection and theorising.

I met interesting people in the other seminars, sharing narratives and reflections about their interaction with their clients and their woven fantasies. Although we discussed theory, no particular technique was taught because the main point was to understand our experiences with socially needy people or psychosomatically ill patients, exposed to meanings through suffering, pain and hope. I was also able to witness the expertise of Mrs. Dilys Daws 
and Mrs. Gianna Williams, learning from their containing and integrating commentaries.

Last but not least, during the programme it was an honour to meet the wise and yet humble couple Mrs. Margaret and Prof. Michael Rustin. Seeking to refine the theoretical and methodological aspects of my thesis, I was supervised by Prof. Rustin, who introduced me to various readings, an expression of his restless, dynamic thinking, expertise and devotion to learning. Our reflections concerned the relevance of Bick's method for research, considering, among other themes, possible links between ethnographic cultural anthropology and psychoanalytic infant observation.

Constructing an understanding of the other implies moving away from the observer's points of personal reference; could this anthropological task of seeing the other as 'otherness' (that is to say the specificity of the 'object of study', the way of life being studied) according to the context that gives meaning to the reality, not as a mirror of the researcher, be broadly explored with the help of unconscious belief?

Geertz, 11 recognized as the main representative of cultural anthropology, gave attention to the meaning-systems of his subjects. His epistemology is the apprehension of meanings as the beliefs, assumptions, norms and values of the communities, groups or individuals studied (the "being there" process). The aim is to construct "from the ground up' a representation of the world as it was lived in symbolic terms by the subjects. An empathetic engagement with their meaning-systems enables one to clarify and elaborate what these are, how they hold together, where within them conflicts and contradictions may arise, how they may evolve through encounters with other meaning-systems. 1,11

Psychoanalytical observation considers the researcher's subjectivity as an instrument of 'knowing' based on the transference phenomena, an understanding of the relationship between what is empirically observed and subjectively experienced during fieldwork. The provisional interpretation from the transference comes in the posteriori; this process of analysing and thinking about our actions is a fundamental requirement for scientific rigor and ethics.

From "being there" to "being here"11 (the academic communication) / from Bick's observational moment to the writing up and seminars, there is an intense, detailed and complex process in constructing meanings rooted in the exchanges built up with the natives / family point of view and the author's desire to communicate and articulate facts, emotions and ideas. In both disciplines there is concern with the legitimacy of what is attributed to the other. In these intersubjective relationships there are no guarantees, no hypotheses to be confirmed; their methodological and analytical uniqueness is the condition for putting interpretations to the test.

The affective traffic within relationships, be it between researcher's and researched or those of participants in their past, present and/or anticipated future, creates a paradigm that may enrich ethnographic research both epistemologically and ontologically speaking: using the researcher subjectivity as 'an instrument of knowing' (epistemology); informing an understanding of participant subjectivity (ontology). 12

The ethnographic text is not an anonymous murmur; an interlocution with psychoanalysis may contribute to a wider reflection on research techniques and new sources of knowledge regarding the affective dialogue of subjectivities and mother-infant relationship as a significant building block of the social system. 13 Perhaps in the field of qualitative research, considering the diversity of disciplines that interact, we can speak of different theoretical or epistemological positions, each of which may endorse a version of ethnographic work. 14

\section{Final considerations}

During the programme I was immersed in an atmosphere of making the most of intense, careful and deep observations, learning put up with my uncertainty and apparent confusion of feelings before rushing into rational, superficial explanations and interpretations full of anxiety. Whereas in the selfcontrolled and reason-built Cartesian scheme, the isolated individual subject is regarded as the essential building block of human experience and understanding, anthropological and psychoanalytical observation puts up with 'not-knowing', seeking for the 'intruder', relying on a method of tuning into the complexity and subtlety of verbal and non-verbal communication.

Although the observations were developed in a variation of the setting, Bick's basic guidelines were respected. Aware of the ethics of the method, Tavistock has been widening its' scope, not seeing it as a unique model to be followed, but a comprehensive way of thinking about human uniqueness, facilitating the researcher's capacity for self-analysis and a diversity of applications. That is why Tavistock is recognised worldwide for placing observation at the heart of training and enhancing ongoing practice.

Regarding intersubjectivity and the experience 
of the 'other', the approaches developed by anthropology and psychoanalysis may have valuable potential applications for researchers and health professionals, seeing both practices as encounters, a space for participation and dialogue, regarding biological, cultural and psychic expressions. They may enable different sensitivities to comprehensive dimensions of experience. They may allow one to see that each person can live within their own world of meanings, and that unless the former tries to 'attend to' those of the latter, one may fail to understand them, or to communicate, failing to give closer attention and weight to those in a socially weaker position in the encounters.

In dealing with the fruitful, broad contemporary field of mother-child health research and attention perhaps we are not faced with a single concept of science, but rather new or renewed paradigms of thought and diversity of research methods.

\section{References}

1. Rustin M. Observing infants: reflections on methods. In: Miller L, Rustin M, Rustin M, Shuttleworth J edits. Closely observed infants. London: Gerald Duckworth \& Co. Ltd.; $1989 / 2009$.

2. Geertz C. A interpretação das culturas. Rio de Janeiro: LTC, 1973/2008.

3. Habermas J. Teoria de la acción comunicativa. 2 ed. España: Taurus; 1988.

4. Habermas J. Teoria de la acción educativa: complementos y estudios previos. Madrid: Cátedra; 1997.

5. Gadamer H-G. A razão na época da ciência. Rio de Janeiro: Tempo Brasileiro; 1983.

6. Costa MCS. Intersubjetividade e historicidade: contribuições da moderna hermenêutica à pesquisa etnográfica. Rev Latino-am Enferm. 2002; 10: 372-82.

7. Rustin M. Esther Bick's legacy of infant observation at the Tavistock: some reflections 60 years on. In: Harris M, Bick E, Williams MH. The Tavistock model: papers on child development and psychoanalytic training. London: Harris Meltzer Trust Series by Karnac Books Ltd; 2011. p. 37590

Recebido em 30 de janeiro de 2012

Versão final apresentada em 16 de fevereiro de 2012

Aprovado em 27 de fevereiro de 2012

\section{Acknowledgements}

This study was supported by FACEPE (Fundação de Amparo à Ciência e Tecnologia do Estado de Pernambuco) and made possible by FAPE/IMIP (Fundo de Apoio à Pesquisa e Ensino do IMIP) and by a grant from CAPES. Special thanks to Instituto de Medicina Integral Prof. Fernando Figueira (IMIP), Trudy Klauber and her staff at Tavistock, Mrs. Ruth Seglow, Mrs. Sharon Shine, Prof. Ricky Emanuel, Mrs. Alison Cantle, Stephania Batista Geraldini and the Brazilian students at Tavistock, all the students with whom I attended the seminars and especially to Stephen Cviic, who, with poetic sensitivity, gave me more than lessons and English words to express what I didn't know how to and wasn't aware of.

8. Bick E. Notes on infant observation in psychoanalytic training. Int J Psycho-Anal. 1964; 45: 558-66.

9. Sternberg J. Infant observation at the heart of training. London: Karnac Books Ltd; 2005.

10. Escandón V. Playing with culture. What is the role of musicality and play in the transmission of culture from mother to infant? Infant Obs. 2008; 11: 257-74.

11. Geertz C. Works and lives: the anthropologist as author. Polity Press, UK; 1988.

12. Hollway W. Applying the 'experience-near' principle to research: Psychoanalytically informed methods. J Soc Work Pract. 2009; 23: 461-74.

13. Rustin MJ. 'Infant observation research: What have we learned so far?' Infant Obs. 2006; 9: 35-52.

14. Atkinson P, Hammersley M. Ethnography and participant observation. In: Denzin NK, Lincoln YS, eds. Strategies of qualitative inquiry. Thousand Oaks, CA: Sage; 1998. p. 110-32. 